Dikirim: 16 Febuari 2017 Diterbitkan: 1 Agustus 2017

\section{Ketahanan hidup dua tahun pasien tuberkulosis resisten obat di RS. Moewardi Surakarta tahun 2010-2014}

\section{Two year survival of drug resistant tuberculosis patients in Moewardi hospital in Surakarta in 2010-2014}

Artika Fristi Firnawati ${ }^{1}$, Riris Andono Ahmad ${ }^{1}$, Heni Retnowulan ${ }^{2}$

Abstract

Purpose: The purpose of this study was to determine the two year survival rate and predictor factors of mortality in drug resistant tuberculosis patients during treatment at the Moewardi Hospital in Surakarta. Methods: This research was a retrospective cohort study of 250 drug resistant tuberculosis patients receiving treatment in the Moewardi Hospital in January 2011-September 2014. Data were analyzed using survival analysis to find factors affecting the 2 year survival. Our variables were demographic factors, disease characteristics and treatment history. We used Cox regression test with 5\% significance level. Results: 2-year survival rates of drug resistant patients was $74.82 \%$. age, the type of patient, HIV status, side effects of medications and culture conversion were significant to survival rate in bivariate analysis. Cox regression test showed that aged $\geq 40$ years (HR 3.221; 95\% Cl 1.037 to 10.001) and have HIV-positive status (HR 18.086; 95\% $\mathrm{Cl} 1.958$ to 167.073 ) were related with reduction of two year survival rate in drug resistant tuberculosis patient. Conclusion: Age above 40 years old and HIV positive status for drug-resistant tuberculosis patients may accelerate their death. The screening of HIV in drug resistant tuberculosis patients is needed in order to increase two year survival rate of patients during treatment.

Keywords: tuberculosis; survival life; drug resistant

\footnotetext{
${ }^{1}$ Departemen Biostatistik, Epidemiologi, dan Kesehatan Populasi, Fakultas Kedokteran, Universitas Gadjah Mada (Email: artika.fristi@gmail.com)

2 Bagian Ilmu Penyakit Dalam, Fakultas Kedokteran, Universitas Gadjah Mada
} 


\section{PENDAHULUAN}

Tuberkulosisresisten obat merupakan keadaan dimana M. tuberkulosis tidak dapat lagi dibunuh oleh obat anti tuberkulosis (OAT), keadaan ini merupakan fenomena buatan manusia, sebagai akibat dari pengobatan pasien tuberkulosis yang tidak adekuat maupun penularan dari pasien tuberkulosis resisten obat $(1,2)$. Tuberkulosis resisten obat dikategorikan monoresisten, poliresisten, multi drug resistant (MDR), Extensively Drug-Resistant (XDR) (1) dan Rifampicin Resistant (RR) (2) yang didapatkan secara sekunder atau primer $(1,3,4)$.

World Health Organization (WHO) menyebutkan pada tahun 2014 terdapat 480.000 kasus (5\% dari kasus) multidrug-resistant berjumlah kematian 190.000 kasus (5). Insiden TB MDR didapatkan pada 3,3\% kasus baru dan $20 \%$ kasus dengan riwayat pengobatan TB sebelumnya (6). Estimasi proporsi insiden TB MDR di Indonesia tahun 2014 sebesar 13,9\% yang terdiri dari $1,9 \%$ pasien baru $12 \%$ kasus dengan riwayat pengobatan TB sebelumnya (6). Kasus TB RR/MDR di Indonesia tahun 2009-2014 menunjukkan peningkatan $(5,7)$ dengan jumlah kumulatif 4.578 kasus (7).

Pengendalian TB resisten obat di Indonesia atau yang dikenal dengan Manajemen Terpadu Pengendalian TB Resisten Obat (MTPTRO) dilakukan sejak pertengahan tahun 2009. Kegiatan MTPTRO di rumah sakit Moewardi Surakarta meliputi penemuan suspek, pengobatan, pemantauan pengobatan, penguatan jejaring ditambah dengan kegiatan berupa bantuan dana trasnportasi pasien, sarasehan bulanan, kelompok dukungan sebaya semangat membara berantas TB (paguyuban semar) dan advokasi kepada pemerintah daerah/kota untuk dana bantuan pasien TB resisten obat (8).

Kasus TB resisten obat di rumah sakit Moewardi Surakarta dari tahun 2010 hingga pertengahan Maret 2016 menunjukkan peningkatan dengan jumlah kumulatif kasus 458 orang (23,27\%) dari 1.968 suspek yang diperiksa. Pasien yang menjalani pengobatan sebesar 359 orang (77,95\%) dengan kematian 91 kasus (25,49\%). Hasil pengobatan menggambarkan bahwa kegiatan pengobatan pasien yang dilakukan belum mencapai tujuan pengobatan, yaitu mencegah kematian (9).

Hasil penelitian di beberapa negara menunjukkan terjadinya kematian pada pasien TB resisten obat sebesar 53,1\% di Korea Selatan (10), 32,6\% di Lithuania (11) $7,8 \%$ di United Kingdom (12) $15,43 \%$ di Ethiopia
(13) $10 \%$ di Haiti (14), $29,5 \%$ di China (15) $38 \%$ di Bulgaria (16) dan 11,8\% di Mesir (17) serta 58\% pada pasien TB XDR di Russia (11). Pasien TB MDR yang telah mendapatkan pengobatan berisiko mengalami kematian 7,8 kali lebih cepat dibandingkan dengan pasien TB yang sensitif obat (18).

Penelitian terkait faktor yang berhubungan dengan ketahanan hidup pasien pada masa pengobatan dari beberapa Negara menunjukkan hasil yang berbedabeda. Penelitian di Lithuania oleh Balabanova et al. menyimpulkan bahwa penggunaan OAT lini 2, pertambahan umur, tempat tinggal di desa, konsumsi alkohol, tidak bekerja, tingkat pendidikan rendah, status HIV positif, adanya kaviti dan BTA positif merupakan faktor prediktor yang memengaruhi ketahanan hidup pasien (11). Penelitian di Ethiopia menunjukkan faktor risiko kematian yang bermakna adalah kebiasaan merokok, keterlambatan pengobatan, HIV positif dan ada komplikasi klinik (13). Penelitian membuktikan faktor risiko yang memiliki hubungan bermakna dengan kematian adalah BTA positif pada awal pengobatan dan kehilangan BB atau BB tidak bertambah pada masa pengobatan (16). Tujuan penelitian untuk mengetahui faktor prediktor yang memengaruhi ketahanan hidup 2 tahun pasien TB resisten obat di rumah sakit Moewardi.

\section{METODE}

Penelitian dilakukan menggunakan rancangan kohort retrospektif. Sampel penelitian adalah pasien TB resisten obat yang telah dan sedang mendapat pengobatan di RS. Moewardi Surakarta periode Januari 2011-September 2014 dengan kriteria eksklusi meninggal sebelum mendapatkan terapi, pindah tempat pengobatan dan pasien dengan data yang tidak lengkap. Pengambilan sampel menggunakan teknik total sampling (exhaustive sampling).

Variabel independen pada penelitian ini adalah faktor karakteristik demografi pasien (umur, jenis kelamin), faktor karakteristik penyakit pasien (resistensi OAT, tipe pasien, status HIV, komorbiditi DM) dan faktor riwayat pengobatan pasien (keterlambatan pengobatan, efek samping, konversi biakan), sedangkan variabel dependen adalah ketahanan hidup 2 tahun pasien TB resisten obat/survival time terhadap kematian. Analisis data menggunakan metode Kaplan meier dan faktor yang bermakna dianalisis dengan cox regression. Penelitian telah mendapatkan kelaiakan etik dari Fakultas Kedokteran Universitas Gadjah Mada. 


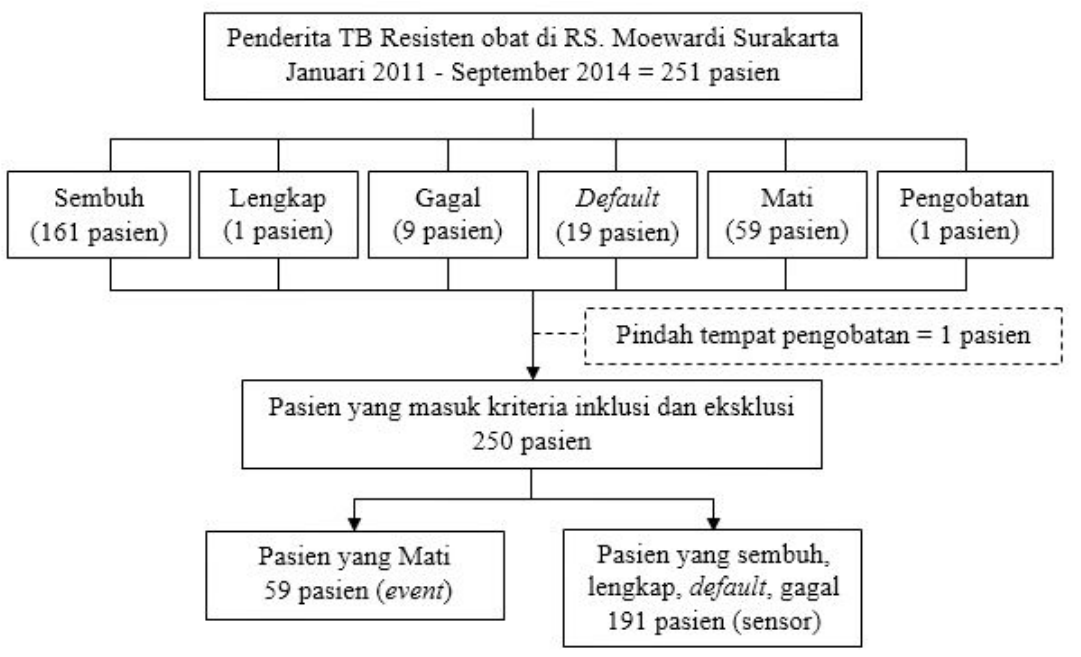

Gambar 1. Bagan alur jumlah penderita TB sampai analisis

\section{HASIL}

Pasien dengan kriteria eksklusi berjumlah 1 pasien sehingga jumlah sampel penelitian sampai analisis sebesar 250 pasien yang terdiri dari $23,60 \%$ mengalami event dan $76,40 \%$ sebagai sensor. Distribusi frekuensi pada pada penelitian disajikan pada Tabel 1 .

Tabel 1. Distribusi frekuensi pasien TB resisten obat

\begin{tabular}{llc}
\hline Variabel penelitian & \multicolumn{1}{c}{ Kategori } & \% (n=250) \\
\hline Umur & $<40$ tahun & 47,60 \\
Jenis Kelamin & $\geq 40$ tahun & 52,40 \\
& Perempuan & 47,60 \\
Resistensi OAT & Laki-laki & 52,40 \\
& Polyresistence & 1,60 \\
& MDR & 51,60 \\
Tipe Pasien & RR & 46,80 \\
& TB Kronis/gagal kategori 2 & 37,60 \\
& Gagal kategori 1 & 23,60 \\
& Gagal kategori 1 tidak & 0,40 \\
& konversi 3 bulan & \\
& pengobatan & \\
& Kambuh kategori & 29,20 \\
& 1/kategori 2 & \\
& Loss to follow up & 8,00 \\
& Koinfeksi HIV tidak & 1,20 \\
Status HIV & merespon OAT & \\
& Negatif & 98,78 \\
Komorbiditi DM & Positif & 1,22 \\
Keterlambatan & Tidak diketahui & 1,60 \\
Pengobatan & Non DM & 66,00 \\
ESO & DM & 34,00 \\
Konversi Biakan & $>1$ bulan & 55,20 \\
& Ringan dan Sedang & 44,80 \\
& Berat & 52,00 \\
& $\leq 2$ bulan & 48,00 \\
& $>2$ bulan & 80,42 \\
& & 19,58 \\
\hline
\end{tabular}

Sebagian besar pasien TB resisten obat berumur $\geq 40$ tahun, berjenis kelamin laki-laki, tipe resistensi OAT MDR, tipe pasien TB kronis/gagal kategori 2, status HIV negatif, tanpa komorbiditi DM, tidak mengalami keterlambatan pengobatan, mengeluh memiliki efek samping ringan/sedang dan konversi biakan terjadi $\leq 2$ bulan. Pasien TB resisten obat yang sedang menjalani pengobatan mengalami efek samping obat (Tabel 2).

Tabel 2. Distribusi frekuensi pasien TB resisten obat berdasarkan efek samping obat

\begin{tabular}{|c|c|c|c|c|c|}
\hline $\begin{array}{l}\text { Efek samping } \\
\text { obat ringan } \\
\text { atau sedang }\end{array}$ & $\mathbf{N}$ & $\%$ & $\begin{array}{c}\text { Efek } \\
\text { samping } \\
\text { obat berat }\end{array}$ & $\mathbf{N}$ & $\%$ \\
\hline Reaksi Kulit & 65 & 26,00 & $\begin{array}{l}\text { Kelainan } \\
\text { fungsi hati }\end{array}$ & 1 & 0,40 \\
\hline Mual muntah & 196 & 78,40 & $\begin{array}{l}\text { Kelainan } \\
\text { fungsi ginjal }\end{array}$ & 8 & 3,20 \\
\hline Anoreksia & 86 & 34,40 & $\begin{array}{l}\text { Perdarahan } \\
\text { lambung }\end{array}$ & 1 & 0,40 \\
\hline Diare & 39 & 15,60 & $\begin{array}{l}\text { Gangguan } \\
\text { elektrolit } \\
\text { berat }\end{array}$ & 16 & 6,40 \\
\hline Nyeri Kepala & 72 & 28,80 & $\begin{array}{l}\text { Gangguan } \\
\text { pendengara } \\
\mathrm{n}\end{array}$ & 104 & 41,60 \\
\hline Vertigo & 33 & 13,20 & $\begin{array}{l}\text { Gangguan } \\
\text { penglihatan }\end{array}$ & 55 & 22,00 \\
\hline Atralgia & 178 & 71,20 & $\begin{array}{l}\text { Gangguan } \\
\text { psikotik }\end{array}$ & 10 & 4,00 \\
\hline $\begin{array}{l}\text { Gangguan } \\
\text { tidur }\end{array}$ & 120 & 48,00 & Kejang & 4 & 1,60 \\
\hline $\begin{array}{l}\text { Gangguan } \\
\text { elektrolit } \\
\text { ringan/sedang }\end{array}$ & 45 & 18,00 & Tendinitis & 0 & 0,00 \\
\hline Drepesi & 64 & 25,60 & $\begin{array}{l}\text { Syok } \\
\text { Anafilaktik }\end{array}$ & 1 & 0,40 \\
\hline $\begin{array}{l}\text { Perubahan } \\
\text { perilaku }\end{array}$ & 17 & 6,80 & & & \\
\hline $\begin{array}{l}\text { Gastritis } \\
\text { Nyeri di } \\
\text { tempat } \\
\text { suntikan }\end{array}$ & 10 & 27,20 & $\begin{array}{l}\text { menyeluruh } \\
\text { dan SJS }\end{array}$ & 1 & 0,40 \\
\hline Metalic Taste & 56 & 22,40 & Hipotiroid & 1 & 0,40 \\
\hline
\end{tabular}

Efek samping obat yang sering dikeluhkan oleh pasien pada masa pengobatan adalah mual muntah setelah minum obat dan atralgia. Efek samping obat yang lain sering muncul adalah gangguan tidur dan gangguan pendengaran. Efek samping obat yang timbul pada setiap pasien berbeda-beda, sebagian besar pasien mengalami efek samping yang tergolong 
ringan/sedang sedangkan efek samping obat berat terjadi pada sebagian pasien.

Hasil analisis bivariat dengan uji log rank menunjukkan bahwa pasien yang berumur $\geq 40$ tahun, tipe pasien gagal kategoti 1 tidak konversi pada tiga bulan pengobatan, status HIV positif, efek samping rigan/sedang dan konversi biakan $>2$ bulan memiliki hubungan yang bermakna terhadap ketahanan hidup 2 tahun pasien TB resisten obat (Tabel 3).

Tabel 3. Analisis bivariat ketahanan hidup 2 tahun pasien TB

\begin{tabular}{|c|c|c|c|c|}
\hline \multirow[t]{2}{*}{ Variabel } & \multirow{2}{*}{$\begin{array}{l}\rho \log \\
\text { rank }\end{array}$} & \multirow{2}{*}{ HR } & \multicolumn{2}{|c|}{ 95\% CI } \\
\hline & & & Lower & Upper \\
\hline \multicolumn{5}{|l|}{ Umur } \\
\hline$<40$ tahun & 0,020 & 1,860 & 1,091 & 3,171 \\
\hline \multirow{2}{*}{\multicolumn{5}{|c|}{$\begin{array}{l}\geq 40 \text { tahun } \\
\text { Jenis Kelamin }\end{array}$}} \\
\hline & & & & \\
\hline Perempuan & 0,939 & 1,019 & 0,611 & 1,700 \\
\hline \multicolumn{5}{|l|}{ Laki-laki } \\
\hline \multicolumn{5}{|l|}{ Resistensi OAT } \\
\hline Polyresistance & 0,122 & - & - & - \\
\hline MDR & & 0,341 & 0,080 & 1,443 \\
\hline $\mathrm{RR}$ & & 0,530 & 0,127 & 2,215 \\
\hline \multicolumn{5}{|l|}{ Tipe Pasien } \\
\hline Gagal kategori 2 & $<0.001$ & & & \\
\hline Gagal kategori 1 & & 0,469 & 0,221 & 0,994 \\
\hline Gagal kategori 1 tidak & & 24,021 & 2,952 & 195,412 \\
\hline \multicolumn{5}{|l|}{$\begin{array}{l}\text { konversi } 3 \text { bulan } \\
\text { pengobatan }\end{array}$} \\
\hline Kambuh kategori & & 0,644 & 0,339 & 1,223 \\
\hline \multicolumn{5}{|l|}{$1 /$ kategori 2} \\
\hline Loss to follow up & & 0,942 & 0,363 & 2,442 \\
\hline $\begin{array}{l}\text { Koinfeksi HIV tanpa } \\
\text { respon OAT }\end{array}$ & \multicolumn{3}{|c|}{ respon OAT } & 12,137 \\
\hline \multicolumn{5}{|l|}{ Status HIV } \\
\hline Negatif & 0,046 & 3,796 & 0,9625 & 15,577 \\
\hline \multicolumn{5}{|l|}{ Positif } \\
\hline \multicolumn{5}{|l|}{ DM } \\
\hline Non DM & 0,110 & 1,522 & 0,905 & 2,560 \\
\hline \multicolumn{5}{|l|}{ Ya } \\
\hline $\begin{array}{l}\text { pengobatan } \\
<=1 \text { bulan }\end{array}$ & 0,878 & 1,040 & 0,623 & 1,737 \\
\hline & & & & \\
\hline \multicolumn{5}{|l|}{ Efek samping obat } \\
\hline Ringan/sedang & 0,002 & 0,446 & 0,260 & 0,766 \\
\hline Berat & & & & \\
\hline \multicolumn{5}{|l|}{ Konversi Biakan } \\
\hline$<=2$ bulan & 0,011 & 3,070 & 1,234 & 7,634 \\
\hline$>2$ bulan & & & & \\
\hline
\end{tabular}

Probabilitas ketahanan hidup seluruh pasien TB resisten obat adalah $84,63 \%$ pada 6 bulan pengobatan; $78,93 \%$ pada 12 bulan pengobatan; 75,75\% pada 18 bulan pengobatan dan $74,82 \%$ pada 24 bulan/2 tahun pengobatan (Gambar 2).

Berdasarkan grafik estimasi survival, penurunan survival terjadi setelah 0,036 bulan sampai 19,5 bulan masa pengobatan. Kematian pasien TB resisten obat lebih banyak terjadi pada tahap pengobatan intensif yaitu 6 bulan pertama pengobatan sebesar 62,71\%.

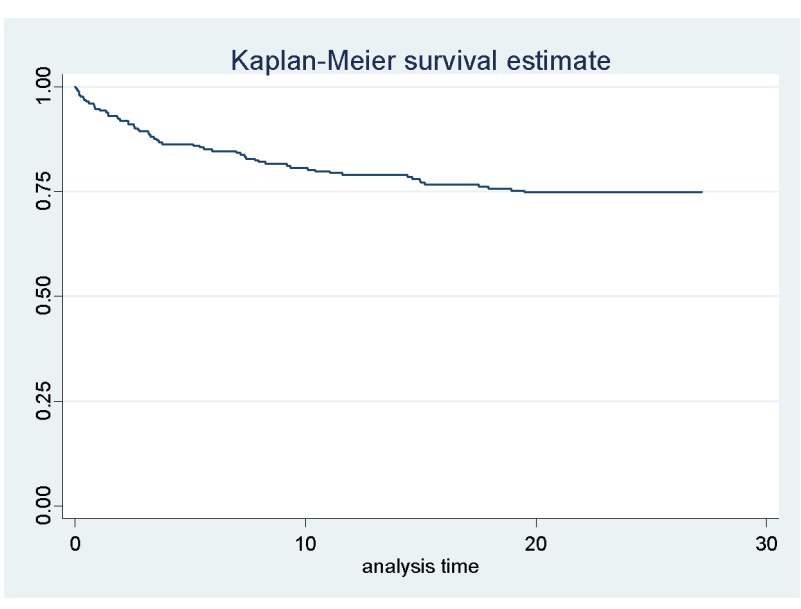

Gambar 2. Kurva Kaplan Meier menunjukkan ketahanan hidup 2 tahun pasien TB Resisten Obat

Variabel yang mempunyai nilai $\rho<0,25$ pada analisis bivariat diuji Goodness Of Fit/GOF (Global test) dan multivariat (cox regressi). Faktor umur ( $\rho$ 0,022) merupakan faktor prediktor yang mempengaruhi ketahanan hidup 2 tahun pasien TB resisten obat. Pasien yang berumur $\geq 40$ tahun berisiko mengalami kematian lebih cepat 1,949 kali dibandingkan dengan pasien yang berumur $<40$ tahun (Tabel 4).

Tabel 4. Analisis multivariat ketahanan hidup 2 tahun pasien TB.

\begin{tabular}{|c|c|c|c|}
\hline \multirow{2}{*}{ Variabel } & \multirow[t]{2}{*}{ HR } & \multicolumn{2}{|c|}{$95 \% \mathrm{CI}$} \\
\hline & & Lower & Upper \\
\hline Umur $\geq 40$ tahun & 4,301 & 1,232 & 15,015 \\
\hline Jenis Kelamin laki-laki & - & - & - \\
\hline Resistensi OAT & & & \\
\hline MDR & 0,356 & 0,024 & 5,274 \\
\hline $\mathrm{RR}$ & 0,316 & 0,022 & 4,530 \\
\hline Tipe Pasien & & & \\
\hline Gagal kategori 1 & 0,503 & 0,133 & 1,896 \\
\hline $\begin{array}{l}\text { Gagal kategori } 1 \text { tidak } \\
\text { konversi } 3 \text { bulan } \\
\text { pengobatan }\end{array}$ & - & - & - \\
\hline $\begin{array}{l}\text { Kambuh kategori } 1 / \text { kategori } \\
2\end{array}$ & 0,348 & 0,072 & 1,673 \\
\hline Loss to follow up & 1,624 & 0,180 & 14,620 \\
\hline $\begin{array}{l}\text { Koinfeksi HIV tanpa respon } \\
\text { OAT }\end{array}$ & 5,355 & 0,338 & 84,740 \\
\hline Status HIV positif & 1 & - & - \\
\hline DM & 0,443 & 0,133 & 1,475 \\
\hline $\begin{array}{l}\text { Keterlambatan } \\
\text { pengobatan }\end{array}$ & - & - & - \\
\hline $\begin{array}{l}\text { Efek samping obat } \\
\text { ringan/sedang }\end{array}$ & 0,540 & 0,177 & 1,644 \\
\hline Konversi Biakan > 2 bulan & 2,490 & 0,815 & 7,606 \\
\hline
\end{tabular}

\section{BAHASAN}

Hasil penelitian menunjukkan bahwa kematian pasien TB resisten obat banyak terjadi pada tahap pengobatan intensif (14,8\%) karena kondisi pasien yang buruk saat datang dan berobat ke rumah sakit. Beberapa kematian pasien $\mathrm{TB}$ resisten obat yang 
terjadi saat rawat inap disebabkan oleh kondisi gagal nafas dan penurunan kesadaran. Angka kematian ini lebih rendah dibandingkan dengan angka kematian di rumah sakit St. Peter's Ethiopia (15,43\%) (13).

Kematian dimungkinkan berhubungan dengan faktor umur $\geq 40$ tahun. Hal ini dikarenakan makin bertambah umur (penuaan) terjadi perubahan fungsi imun tubuh, kecepatan respon imun tubuh dalam melawan infeksi menurun (19) sehinnga respon terhadap OAT kurang dan waktu pemulihan lebih lambat (20). Pasien TB resisten obat yang ber umur $\geq 40$ tahun memiliki risiko mengalami kematian 4,301 lebih cepat dibandingkan dengan pasien yang berumur $<40$ tahun (HR 4,301; 95\% CI 1,232 - 15,015).

Hasil penelitian ini sejalan dengan penelitian lain $(10,11,20,21)$, dimana umur merupakan faktor prediktor yang berhubungan dengan ketahanan hidup pasien TB resisten obat. Hasil penelitian pasien TB MDR di Pakistan yang berumur $\geq 44$ tahun dengan bertambahannya umur setiap tahunnya dapat meningkatkan kematian 0,183 kali lebih cepat $(\operatorname{Exp} \beta$ $0,183 ; \quad \rho$-value 0,$001 ; 95 \%$ CI $0,064-0,521) \quad(20)$, sedangkan pasien TB MDR berumur $>45$ tahun akan mengalami kematian lebih besar 1,99 dibandingkan pasien TB MDR berumur <25 tahun (RR 1,9; 95\% CI 1,29-2,80) (21).

Waktu terjadinya konversi kultur pada pemeriksaan dahak pasien $>2$ bulan memiliki hubungan yang bermakna dengan kematian pasien TB resisten obat pada masa pengobatan (HR 3,070; 95\% CI 1,235-7,634). Hal ini dikarenakan lama waktu konversi biakan dapat mempengaruhi lama pengobatan dan dapat meningkatkan terjadinya kematian pada masa pengobatan. Hasil penelitian ini tidak sejalan dengan hasil penelitian di India bagian barat (22), pasien TB MDR dengan waktu konversi lebih dari 3 bulan mempengaruhi hasil pengobatan yang tidak sukses ( $\rho$ 0,0001). hasil penelitian sebelumnya di RS. Moewardi Surakarta, pasien TB resisten obat yang mengalami konversi biakan $>2$ bulan berisiko mengalami hasil pengobatan yang buruk sebesar 0,497 kali dibandingkan dengan pasien TB resisten obat yang mengalami konversi $\leq 2$ bulan (23). Perbedaan penelitian ini dikarenakan jenis analisis dan kategori hasil pengobatan.

Faktor lain yang berhubungan dengan ketahanan hidup 2 tahun pasien TB resisten obat adalah tipe pasien gagal kategori 1 yang tidak mengalami konversi pada bulan ketiga dan timbulnya efek samping obat ringan atau sedang. Tetapi dua faktor prediktor berbanding terbalik dengan teori yag ada, hal ini dikarenakan rancangan penelitian menggu-nakan kohort retrospektif, peneliti tidak bisa mengendalikan data yang ada serta ada data yang missing.

kategori resistensi OAT, komorbiditi DM dan keterlambatan dalam mendapatkan pengobatan tidak berhubungan dengan ketahanan hidup 2 tahun pasien TB resisten obat. Hasil penelitian ini berbeda dengan hasil beberapa penelitian sebelumnya tentang faktor prediktor yang memengaruhi ketahanan hidup pasien TB resisten obat dimana faktor resistensi OAT (24), komorbiditi DM (25) dan keterlambatan pengobatan (13) merupakan faktor prediktor kematian pasien TB resisten obat. Penelitian ini memiliki beberapa keterbatasan terkait dengan ranca-ngan penelitian kohort retrospektif dan tidak semua pasien melakukan uji kepekaan OAT atau diagnosis kepekaan OAT pada pasien hanya berdasarkan hasil rapid test.

\section{SIMPULAN}

Umur pasien TB resisten obat yang berumur $\geq 40$ tahun dan status HIV positif merupakan faktor prediktor yang dapat memengaruhi ketahanan hidup pada masa pengobatan. Upaya penemuan dini pasien TB resisten obat pada umur $<40$ terutama pada pasien dengan status HIV positif sehingga diharapkan dapat menurunkan angka morbiditas dan mortalitas pasien TB resisten obat pada masa pengobatan. Perlu adanya penelitian lebih lanjut untuk meneliti faktor prognosis hasil pengobatan pasien TB resisten obat secara prospektif.

\footnotetext{
Abstrak

Tujuan: Tujuan penelitian ini adalah untuk mengetahui angka ketahanan hidup 2 tahun dan faktor prediktor kematian pasien pada masa pengobatan di Rumah Sakit Moewardi Surakarta. Metode: Penelitian kohort retrospektif dilakukan pada 250 pasien TB resisten obat yang mendapatkan pengobatan pada Januari 2011-September 2014. Analisis data menggunakan metode kapplan meier cox regression. Hasil: Ketahanan hidup 2 tahun pasien TB resisten obat adalah 74,8\%. Perbandingan probabilitas ketahanan hidup antar kelompok yang menunjukkan perbedaan dalam memengaruhi ketahanan hidup 2 tahun adalah umur, tipe pasien, status HIV, efek samping obat dan konversi biakan. Faktor prediktor yang memengaruhi ketahanan hidup 2 tahun pasien TB resisten obat adalah umur $\geq 40$ tahun (HR 3,2; 95\% CI 1,0-10,0) dan status HIV positif (HR 18,1; 95\% CI 2,0-167,1). Simpulan:
} 
Pertambahan umur dan status HIV positif pasien TB resisten obat mempercepat kematian pasien pada masa pengobatan. Diperlukan skrining TB resisten obat pada pasien HIV positif guna menurunkan angka morbiditas dan mortalitas pasien pada masa pengobatan.

Kata Kunci: tuberkulosis; ketahanan hidup; resisten obat

\section{PUSTAKA}

1. Curry International Tuberculosis Center. Drug-Resistant Tuberculosis a Survival Guide for Clinicians. In: Clinics in Chest Medicine. 2nd ed. California Department of Public Health; 2011. www.currytbcenter.ucsf.edu/drtb.

2. Kementerian Kesehatan RI. Petunjuk Teknik Manajemen Terpadu Pengendalian Tuberkulosis Resistan Obat. Jakarta: Direktorat Jenderal Pengendalian Penyakit dan Penyehatan Lingkungan; 2013. doi:10.1017/CBO9781107415324.004.

3. Soepandi, P Z. Diagnosis dan Penatalaksanaan Tb MDR. Cermin Dunia Kesehat. 2010;37(7):497-501.

4. WHO. Companion Handbook To The WHO Guidelines For The Programmatic Management of Drug-Resistant Tuberculosis. Geneva; 2014.

5. WHO. Multidrug Resistant Tuberculosis (MDR-TB) 2015 Update.; 2015.

6. WHO. Global Tuberculosis Report 2015. Vol 1. 20th ed.; 2015. doi:10.1017/CBO9781107415324.004.

7. Kemenkes RI. Tuberkulosis Temukan Obati Sampai Sembuh. Infodatin. 2015:2-3. http://www.depkes.go.id/download.php?file=down load/pusdatin/infodatin/infodatin_tb.pdf.

8. Ratna. Profil Program Pengendalian TB Propinsi Jawa Tengah. Surakarta: P2TB Jawa Tengah; 2014.

9. Kementerian Kesehatan RI. Pedoman Nasional Pengendalian Tuberkulosis. Jakarta: Direktorat Jenderal Pengendalian Penyakit dan Penyehatan Lingkungan; 2014.

10. Kim DH, Kim HJ, Park S-K, et al. Treatment outcomes and long-term survival in patients with extensively drug-resistant tuberculosis. Am J Respir Crit Care Med. 2008;178(10):1075-1082. doi:10.1164/rccm.200801-1320C.

11. Balabanova Y, Radiulyte B, Davidaviciene E, et al. Survival of Drug Resistant Tuberculosis Patients in Lithuania: Retrospective National Cohort Study. BMJ Open. 2011;1(2):e000351-e000351. doi:10.1136/bmjopen-2011-000351.

12. Anderson LF, Tamne S, Watson JP, et al. Treatment Outcome of Multi-drug Resistant Tuberculosis in The United Kingdom: Retrospective-Prospective Cohort Study From 2004 to 2007. Euro Surveill. 2013;18(40):1-10.

doi:10.2807/1560-7917.ES2013.18.40.20601.
13. Getachew T, Bayray A, Weldearegay B. Survival and Predictors of Mortality Among Patients Under Multi-drug Resistant Tuberculosis Treatment in Ethiopia: St. Peter's Specialized Tuberculosis Hospital, Ethiopia. Int J Pharm Sci Res. 2013;4(2):776-787.

14. Charles M, Vilbrun SC, Koenig SP, et al. Treatment Outcomes for Patients with Multidrug-Resistant Tuberculosis in Post-Earthquake Port-au-Prince, Haiti. Am J Trop Med Hyg. 2014;91(4):715-721. doi:10.4269/ajtmh.14-0161.

15. Sun Y, Harley D, Vally H, Sleigh A. Comparison of Characteristics and Mortality in Multidrug Resistant (MDR) and Non-MDR Tuberculosis Patients in China. BMC Public Health. 2015;15(1):1027. doi:10.1186/s12889-015-2327-8.

16. Milanov V, Falzon D, Zamfirova M, et al. Factors associated with treatment success and death in cases with multidrug-resistant tuberculosis in Bulgaria, 2009-2010. Int J Mycobacteriology. 2015;4(2):131-137. doi:10.1016/j.ijmyco.2015.03.005.

17. Gadallah MA, Mokhtar A, Rady M, El-Moghazy E, Fawzy M, Kandil SK. Prognostic Factors of Treatment among Patients with Multidrug-Resistant Tuberculosis in Egypt. J Formos Med Assoc. 2015:1-7. doi:10.1016/j.jfma.2015.10.002.

18. Lockman S, Kruuner A, Binkin N, et al. Clinical Outcomes of Estonian Patients with Primary Multidrug-Resistant versus Drug-Susceptible Tuberculosis. Clin Infect Dis. 2001;32(3):373-380. doi:10.1086/318489.

19. Fatmah. Respons Imunitas yang Rendah pada Tubuh Manusia Usia Lanjut. Makara Kesehat. 2006;10(1):47-53.

20. Khan MA, Mehreen S, Basit A, Khan RA, Javaid A. Predictors of Poor Outcomes among Patients Treated for Multidrug-Resistant Tuberculosis at Tertiary Care Hospital in Pakistan. 2015;7(3):162-172. doi:10.5829/idosi.aejts.2015.7.3.9499.

21. Kurbatova E V, Taylor A, Gammino VM, et al. Predictors of poor outcomes among patients treated for multidrug-resistant tuberculosis at DOTS-plus projects. Tuberculosis. 2012;92(5):397-403. doi:10.1016/j.tube.2012.06.003.

22. Jain K, Desai M, Solanki R, Dikshit RK. Treatment outcome of standardized regimen in patients with multidrug resistant tuberculosis. 2014;5(2):145-149. doi:10.4103/0976-500X.130062.

23. Siswanto; Reviono; Aphridasari, Jatu; Susanto YS. Faktor Prediktor Hasil Akhir Pengobatan Pasien Tuberkulosis Resisten Obat di RSUD Dr Moewardi Surakarta. 2016:1-13.

24. Tang S, Tan S, Yao L, et al. Risk Factors for Poor Treatment Outcomes in Patients with MDR-TB and XDR-TB in China: Retrospective Multi-Center Investigation. 2013;8(12):1-8 doi:10.1371/journal.pone.0082943.

25. Leimane V, Riekstina V, Holtz TH, et al. Clinical Outcome of Individualised Treatment of Multidrug Resistant Tuberculosis in Latvia : A Retrospective Cohort Study. Lancet. 2005;365. 